\title{
A Pilot Study of the Sludge Recycling Enhanced Coagulation-Ultrafiltration Process for Drinking Water: The Effects of Sludge Recycling Ratio and Coagulation Stirring Strategy
}

\author{
Bin Liu ${ }^{1,2}$, Fangshu Qu ${ }^{1, *}$, Shaodong Guo ${ }^{1}$, Huarong $\mathrm{Yu}^{1}{ }^{1}$, Guibai $\mathrm{Li}^{1}{ }^{1}$, Heng Liang ${ }^{1}$ and \\ Bart Van der Bruggen ${ }^{2, *}$ \\ 1 State Key Laboratory of Urban Water Resource and Environment (SKLUWRE), \\ Harbin Institute of Technology, Harbin 150090, China; ahxclb@163.com (B.L.); \\ guoshaodong@126.com (S.G.); huarongyu@gmail.com (H.Y.); \\ liguibai@vip.163.com (G.L.); hitliangheng@163.com (H.L.) \\ 2 Department of Chemical Engineering, Process Engineering for Sustainable Systems (ProcESS), \\ KU Leuven, Celestijnenlaan 200F, B-3001 Leuven, Belgium \\ * Correspondence: qufangshu@163.com (F.Q.); bart.vanderbruggen@cit.kuleuven.be (B.V.d.B.); \\ Tel.: +86-451-86282252 (F.Q.); +32-16-322340 (B.V.d.B.); Fax: +86-451-86283001 (F.Q.); +32-16-322991 (B.V.d.B.)
}

Academic Editor: Stephen Gray

Received: 23 December 2016; Accepted: 2 March 2017; Published: 5 March 2017

\begin{abstract}
The pilot-scale study on a sludge recycling enhanced coagulation-ultrafiltration (UF) process for surface water treatment is investigated in this paper. The impact of the sludge recycling ratio and coagulation stirring strategy on removal, sedimentation efficiency, and membrane fouling control was studied in this work. Sludge recycling ratios of $0 \%, 5 \%, 10 \%, 15 \%$, and $20 \%$ were applied, and the optimal ratio was found to be $10 \%$. Moreover, four stirring strategies were also applied, and the best stirring strategy for coagulation was found to be rapid mixing (velocity gradient: $280 \mathrm{~s}^{-1}$ ), which is quite different from the coagulation stirring strategy without sludge recycling. This suggests that the adsorption effect of sludge could play a leading role during the procedure. Moreover, shortening the coagulation process makes it possible to reduce energy consumption.
\end{abstract}

Keywords: pilot study; sludge recycling ratio; coagulation stirring; ultrafiltration

\section{Introduction}

In the context of surface water pollution, drinking water treatment is facing a severe challenge to ensure that the produced water meets all water quality standards [1]. The traditional water treatment processes have their limitations in securing drinking water safety, because of their poor efficiency at removing dissolved organic contaminants and nitrogen.

In China, more and more water treatment plants are applying membrane processes for drinking water treatment. Ultrafiltration (UF), a low-pressure membrane process, has a potential for wide application in large-scale waterworks [2] because it has a high solid-water separation ability. However, membrane fouling is the Achilles heel in the application of UF, so that enhanced pretreatment prior to UF should be utilized to reduce membrane fouling [3]. Another challenge for UF is its low efficiency in removing dissolved organic matter (DOM) [4]. A pretreatment, which can efficiently remove DOM, has great potential in establishing a hybrid system with UF for drinking water security purposes [5].

Coagulation is a well-known process in the drinking water treatment field. Most waterworks apply the coagulation process as the principal pretreatment [6]. DLVO theory is considered the main mechanism for coagulation treatment, especially during the initial period of coagulation [7]. In this 
theory, van der Waals attraction and electrostatic repulsion were the two main forces that impact the colloidal particle stability and growth after the initial period of floc generation and growth [8]. The coagulant dosage could promote floc growth by compressing the electrical layer, adsorption charge neutralization, and the adsorption bridging effect. The three effects were all utilized to minimize the electrostatic repulsive force [9].

In the combined system of coagulation and sedimentation, sludge is produced in the bottom of the sedimentation tank and periodically discharged. Application of sludge recycling instead of directly discharging could take full advantage of the sludge for improving the performance of drinking water treatment [10]. Sludge recycling is a practice known in the wastewater treatment field, since sludge has been proven to be capable of purifying water [11]. The main advantages of the sludge recycling approach are as follows:

1. A high efficiency of adsorption, which allows for enhanced removal of dissolved organics.

2. A high efficiency of coagulation enhancement; the high concentration of the sludge has a better sedimentation potential.

3. The sludge provides suitable conditions for microorganism growth, which allows for the removal of biodegradable substances, and ammonia.

4. The sludge recycling could decrease the coagulant dosage.

In this work, a pilot-scale study on the impact of sludge recycling on the performance of a coagulation/UF process was investigated. The effect of the sludge recycling ratio and coagulation stirring strategy on the removal of colloids, organics, and ammonia are discussed. The sludge recycling ratio is one of the key factors, since a high ratio could impede treatment by hindering sedimentation. An optimum sludge recycling ratio should be obtained first. When sludge is added, the solid content in the raw water increases, which may change the water characteristics. In such conditions, the DLVO theory applied in the traditional coagulation process might not be suitable anymore. Therefore, choosing an appropriate coagulation stirring period to adjust to the new water characteristics can significantly shorten the coagulation stirring time and yield a rapid and complete mixing of sludge and water; the continuous stirring might impede the precipitation of sludge. From the authors' perspective, no previous study has investigated the coagulation stirring strategy during the sludge recycling enhanced coagulation-UF process.

\section{Methods and Materials}

\subsection{Raw Water Characteristics}

The pilot scale study was undertaken in Nanjiao Water Treatment Plant, Dongying, Shandong province, China. The raw water was taken from the reservoir of the Yellow River, which is a typical source of raw water in northern China [12]. Detailed information about the raw water quality is given in Table 1. Since the ammonia concentration is not high in the reservoir water, a dosage of ammonium chloride was applied in this study. The ammonia concentration was kept constant at $1.5 \mathrm{mg} \cdot \mathrm{NH}^{4+} / \mathrm{L}$. The concentration of organics in raw water was evaluated with reference to dissolved organic carbon (DOC) and ultraviolet absorbance at the wavelength of $254 \mathrm{~nm}\left(\mathrm{UV}_{254}\right)$. Prior to the measurement, a $0.45-\mu \mathrm{m}$ filter was used to remove the colloids in the raw water. The dominant algae species were green algae and diatom, and the total number of these algae were determined using a standard blood cell counting chamber [13]. Likewise, the total bacteria were determined using an agar medium [14]. The concentrations of algae and bacteria varied in the range of $3.5-4.5 \times 10^{4} \mathrm{cell} \cdot \mathrm{mL}^{-1}$ and 20-50 CFU $\cdot \mathrm{mL}^{-1}$, respectively. 
Table 1. Raw water quality in this study.

\begin{tabular}{ccc}
\hline Parameter & Unit & Value \\
\hline Temperature & ${ }^{\circ} \mathrm{C}$ & $20-25$ \\
Turbidity & $\mathrm{NTU}$ & $8-15$ \\
DOC & $\mathrm{mg} \cdot \mathrm{L}^{-1}$ & $2.40-3.10$ \\
$\mathrm{UV}_{254}$ & $\mathrm{~cm}^{-1}$ & $0.050-0.065$ \\
$\mathrm{pH}$ & $/$ & $7.8-8.2$ \\
Algae & $10^{4} \mathrm{Cell} \cdot \mathrm{mL}^{-1}$ & $3.5-4.5$ \\
Bacteria & $\mathrm{CFU} \cdot \mathrm{mL}^{-1}$ & $20-50$ \\
\hline
\end{tabular}

\subsection{Pilot Study Protocol}

The pilot-scale study comprised four treatment parts: a four-stage coagulation stirring tank, inclined tube settling tank, a sludge recycling system, and an immersed UF membrane tank. The coagulation stirring tanks were installed in series, and each of the tanks could be connected directly to the sediment tank. The volumes of the four stage stirring tanks were $0.30 \mathrm{~m}^{3}, 0.38 \mathrm{~m}^{3}$, $0.50 \mathrm{~m}^{3}$, and $0.78 \mathrm{~m}^{3}$, respectively. The variation in the volume of the stirring tanks was used to control the value of coagulation GT (coagulation velocity gradient $\times$ time). Moreover, the stirring speed of the stirred tanks enabled the velocity gradient to be set. The stirring speed of these tanks was $150 \mathrm{r} / \mathrm{min}$, $80 \mathrm{r} / \mathrm{min}, 40 \mathrm{r} / \mathrm{min}$, and $20 \mathrm{r} / \mathrm{min}$, respectively. The velocity gradient could be calculated by the stirring speed and dimension of coagulation tank. The velocity gradient of the four tanks was $280 \mathrm{~s}^{-1}$, $120 \mathrm{~s}^{-1}, 50 \mathrm{~s}^{-1}$, and $15 \mathrm{~s}^{-1}$. Aluminum polychloride was used as the coagulant and the dosage was $4 \mathrm{mg} \cdot \mathrm{Al}^{3+} / \mathrm{L}$. The inclined tube in the upward flowing settling tank had a length of $1500 \mathrm{~mm}$, a width of $800 \mathrm{~mm}$, and an inclination angle of $60^{\circ}$. The treatment capacity of the coagulation and sediment unit was $4 \mathrm{~m}^{3} \cdot \mathrm{h}^{-1}$. The sludge at the bottom of the settling tank was collected every $8 \mathrm{~h}$ for the sludge recycling [15]. A 3- $\mathrm{m}^{3}$ container was used to collect the sludge, and a Lange pump was utilized for recycling the sludge into the first stirred coagulation tank. The solid content of sludge was controlled within the range of $4 \%$ to $5 \%$. Figure 1 shows a schematic diagram of the drinking water treatment including coagulation, sediment, membrane, and sludge recycling system.

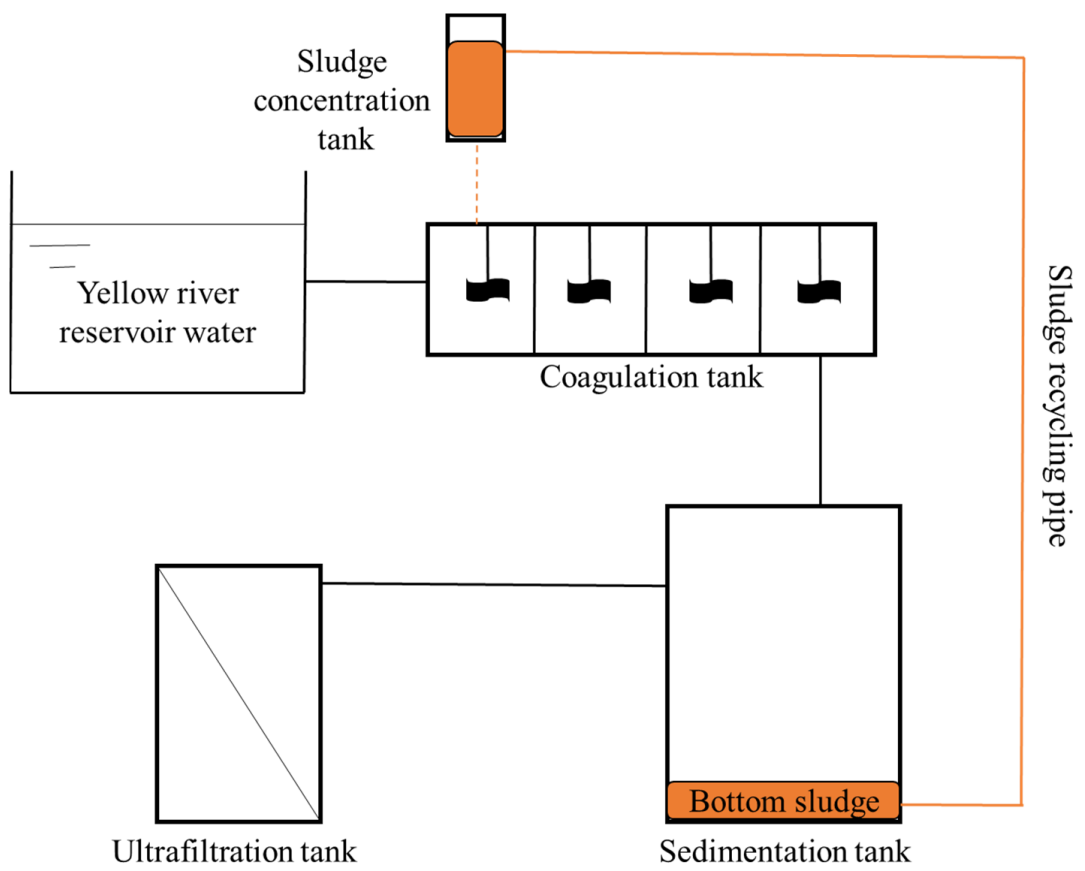

Figure 1. Schematic diagram of the pilot drinking water treatment. The water pipe uses the black line and the sludge pipe uses the orange line. 
The hollow fiber UF membrane was composed of polyvinyl chloride (PVC) (Litree, Hainan, China). The molecular weight cutoff of the hollow fiber membrane used in the immersed UF system was $100 \mathrm{kDa}$. The effective membrane area was $30 \mathrm{~m}^{2}$. The permeate flux applied in this study was $40 \mathrm{~L} \cdot \mathrm{m}^{-2} \cdot \mathrm{h}^{-1}$. Due to the deposition of particles and colloids, the membrane was gradually fouled with the filtration proceeded, resulting in increased TMP. To remove the fouling, the membrane was backward flushing every $2 \mathrm{~h}$ at a flux of $80 \mathrm{~L} \cdot \mathrm{m}^{-2} \cdot \mathrm{h}^{-1}$. The fouling, which could be restored by backwashing, was regarded as reversible fouling, whereas the residual fouling was irreversible fouling.

\subsection{Analytical Methods}

In this work, the ammonia concentration was determined by the Nessler reagent spectrophotometry method. DOC concentrations were measured using a total organic carbon analyzer (multi N/C 2100S, Analytic Jena, Jena, Germany). The $\mathrm{UV}_{254}$ was determined using a UV spectrometer (T6, Puxi, China). It should be noticed that during the investigation of the sludge recycling ratio, the indicators were sampled before the UF process, which could reflect the improving efficiency of sludge recycling [16]. During the investigation of the coagulation stirring strategy, the indicators were sampled after the UF process, which could reflect the removal efficiency of enhanced coagulation-UF. The transmembrane pressure (TMP) was measured with a pressure gauge. The size distribution of the sludge was investigated by a laser particle analyzer (Masterseizer 2000, Malvern, UK), with a valid measurement range of $0.02-2000 \mu \mathrm{m}$.

The removal efficiency was calculated by the following equation, where $\mathrm{C}_{\text {eff }}$ represents the concentration of effluent; $C_{\text {inf }}$ represents the concentration of influent:

$$
\operatorname{removal}(\%)=1-\frac{\mathrm{C}_{\text {eff }}}{\mathrm{C}_{\mathrm{inf}}}
$$

\section{Results}

\subsection{Effects of the Sludge Recycling Ratio on the Coagulation Performance}

Ammonia frequently appears in the aquatic environment and may be a disturbing contaminant in drinking water treatment. Most traditional drinking water treatment methods such as coagulation, sedimentation, and sand filtration have a limited effect in removing the ammonia [17-19]. Membrane processes like microfiltration and UF show low removal efficiency for ammonia, although the membrane can provide a highly efficient separation of solids from water [20]. Figure 2 presents the ammonia removal efficiencies by coagulation at different sludge recycling ratios. When no sludge is recycled in the coagulation process, the ammonia removal efficiency is extremely low $(7 \%)$, which demonstrates that the traditional coagulation-sedimentation process is ineffective at removing the ammonia, which is soluble. This is in accordance with other studies on ammonia removal by coagulation [21]. However, when the sludge recycling was applied to enhance coagulation, the ammonia removal efficiency improved, especially at a sludge recycling ratio above $10 \%$. The ammonia removal ratio was $37.9 \%$ at the sludge recycling ratio of $5 \%$; the removal efficiency increased to more than $60 \%$ when the recycling ratio exceeded $10 \%$. The results indicate that sludge recycling could help improve ammonia removal during coagulation for drinking water treatment. The probable reason for the enhanced ammonia removal is increased microbial amounts due to the sludge recycling. The sludge retention time was prolonged so that the nitrification bacteria could multiply and take effect in the microbial degradation of ammonia [22,23]. It can be observed that the enhancement substantially increased with the sludge recycling ratio when it was below $10 \%$. When the sludge recycling ratio exceeded $10 \%$, the removal ratio of ammonia increased at a very slow rate. This suggests that a $10 \%$ recycling ratio is optimal in view of ammonia removal. 


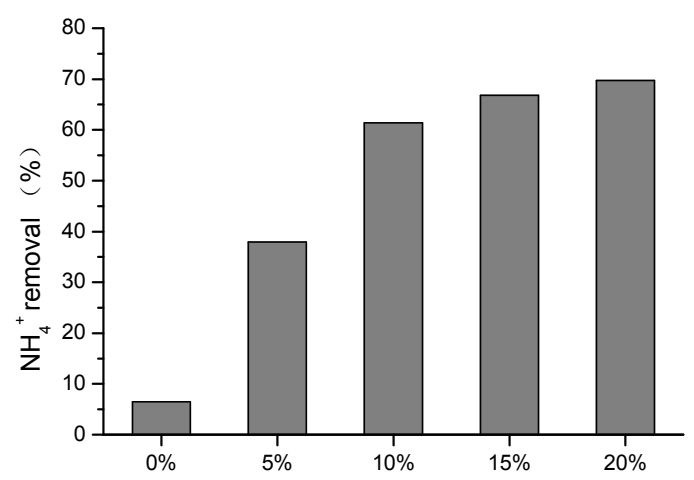

Figure 2. Ammonia nitrogen removal efficiencies observed at different sludge recycling ratios.

The DOC concentration represents the amount of dissolved organics in raw water and $\mathrm{UV}_{254}$ represents the amount of unsaturated organic compounds with conjugated double bonds. A previous study showed that these two indices were related to UF membrane foulants [24]. In this study, these two organic parameters were adopted to investigate the coagulation efficiency and thus the impact of coagulation on the fouling of UF membranes. Figure 3 shows the organic matter removal efficiency by the sludge recycling enhanced coagulation process at different recycling ratios. For the controlled scenario in which sludge recycling was not applied, the removal ratios of DOC and $\mathrm{UV}_{254}$ were $8.8 \%$ and $5.6 \%$, respectively, indicating the poor performance of coagulation in removing the dissolved organics. When the coagulation process was assisted by sludge recycling, the organic removal efficiency was improved to a certain extent. Specifically, as far as DOC was concerned, the removal ratios were $19 \%, 21 \%, 23 \%$, and $22 \%$ at the sludge recycling rate of $5 \%, 10 \%, 15 \%$, and $20 \%$, respectively. Regarding $\mathrm{UV}_{254}$, the removal ratios were $11.79,13.48,16.71$, and 17.46 at the sludge recycling rate of $5 \%, 10 \%$, $15 \%$, and $20 \%$, respectively. The result indicates that the organic removal efficiency generally improved with increased sludge recycling ratios, but the improvement was limited. This differs from the result of ammonia removal.
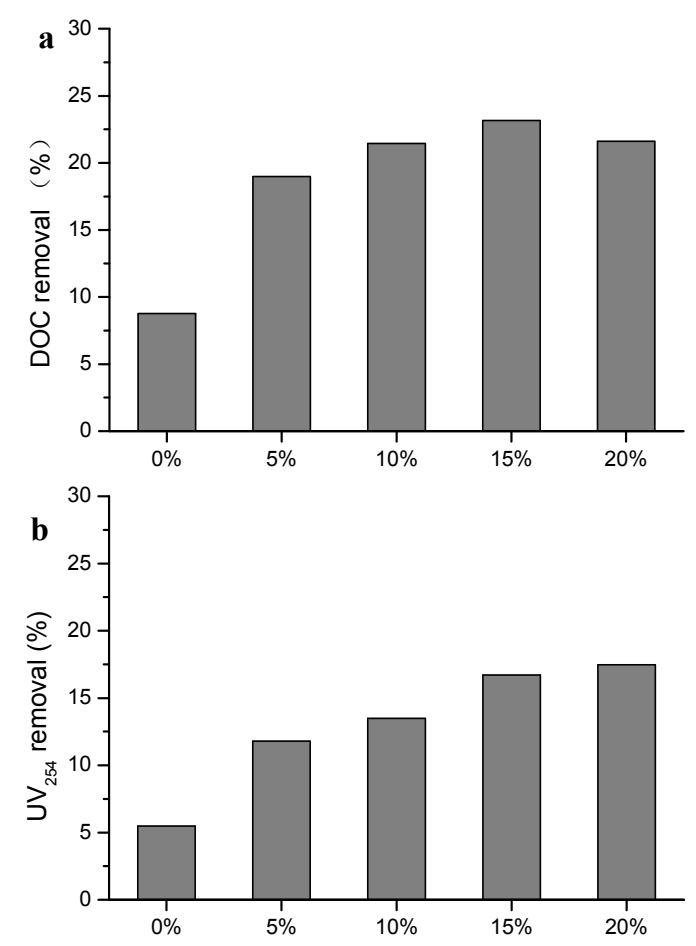

Figure 3. DOC (a) and $\mathrm{UV}_{254}$ (b) removal efficiencies at different sludge recycling ratios. 
The key factors for enhanced coagulation system include not only the performance of ammonia and organic removal, but also the sedimentation efficiency. When the optimum sludge recycling was determined and applied, the overall impact of the sludge recycling on the sedimentation efficiency of flocs should be considered. The operator should shorten the duration of the sedimentation process, and reduce the risk of floc flow through the membrane tank. Figure 4 shows the sedimentation efficiency of the flocs at different sludge recycling ratios with respect to the time required for half height sedimentation. When the sludge recycling ratio exceeded $5 \%$, a boundary line between the flocs and the water layer appeared after the stirring finished. A potential parameter for evaluation is the time of this boundary line to drop down to half height; this sedimentation time index $\left(\mathrm{T}_{1 / 2}\right)$ reflects the sedimentation efficiency of the sludge recycling enhanced coagulation process. In this study, the $\mathrm{T}_{1 / 2}$ represents the time consuming with solid-water boundary drop down to half height of the surface. A lower $\mathrm{T}_{1 / 2}$ means higher sedimentation efficiency. The results show that the sedimentation efficiency was high when the recycling ratios were $5 \%$ and $10 \%$, (349 s and $368 \mathrm{~s}$, respectively). However, the recycle ratio is further increased, $\mathrm{T}_{1 / 2}$ increased sharply: $\mathrm{T}_{1 / 2}$ at a sludge recycling ratio of $15 \%$ and $20 \%$ were $598 \mathrm{~s}$ and $873 \mathrm{~s}$. This suggests that further increasing the sludge recycling ratio would not only increase the operational cost but also impede the overall water treatment system efficiency, although the ammonia and organics removal is improved by an increase in the recycling ratio. However, the sludge recycling ratio should guarantee both good removal efficiency and good sedimentation efficiency. A sludge recycling ratio of $10 \%$ is the optimum ratio and a good compromise between both aspects.

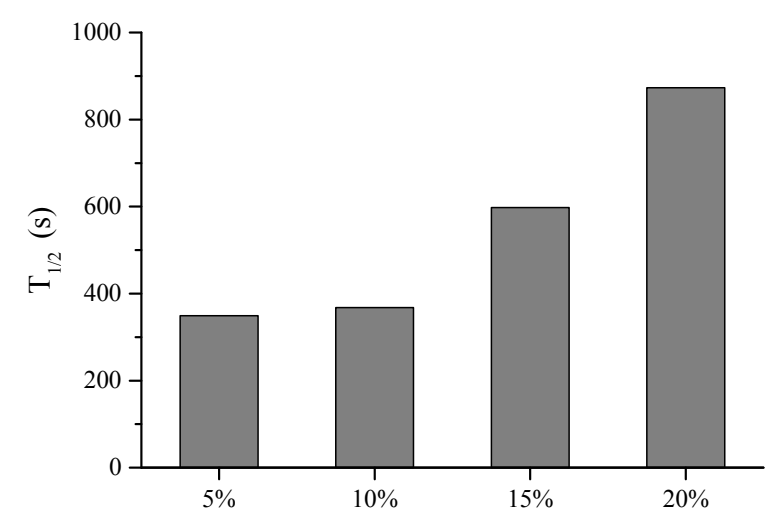

Figure 4. Sedimentation efficiencies at different sludge recycling ratios.

\subsection{Impact of Sludge Recycling Ratio on the UF Membrane Fouling}

Figure 5 shows the TMP profiles during filtration of feed solutions with different sludge recycling ratios. Figure 5a shows the increase of the TMP with different sludge recycling ratios. The results demonstrate that membrane fouling is mitigated when the sludge recycling ratio is below $15 \%$; however, when the sludge recycling ratio is $20 \%$, no alleviation of membrane fouling was observed. This might be related to the low sedimentation efficiency, which leads to more flocs flowing into the membrane tank. This also indicates that the sedimentation efficiency should be considered carefully during process design. Thus, when the sludge recycling ratio is carefully controlled, the membrane fouling could be mitigated. A sludge recycling ratio of $10 \%$ alleviates membrane fouling with the highest efficiency.

Figure $5 \mathrm{~b}$ shows the reversibility of membrane fouling at day 10. The TMP before backflush minus the TMP after backflush represents the reversible membrane fouling. The TMP after backward flushing minus the initial TMP represents the irreversible membrane fouling. Both reversible fouling and irreversible fouling may impact the operation of the UF process, but since reversible membrane fouling can easily be removed by hydrodynamic cleaning such as forward flushing and backward flushing, irreversible fouling is the most cumbersome during membrane operation. The results show 
that the application of sludge recycling may reduce membrane fouling, which suggests that sludge recycling is a viable way to control membrane fouling. The irreversible fouling was the lowest at a sludge recycling ratio of $10 \%$, which is in accordance with the removal efficiency and the sedimentation efficiency presented in Section 3.1.
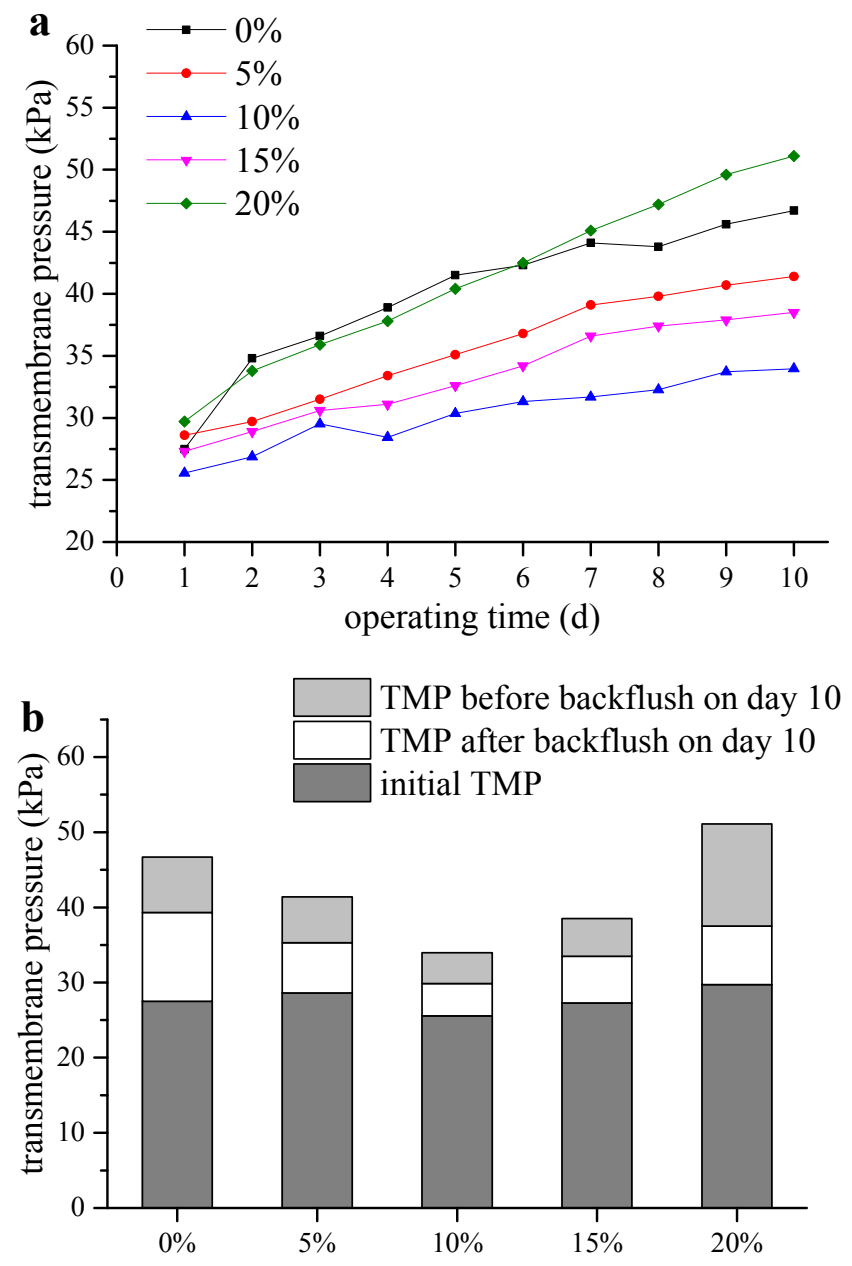

Figure 5. TMP with different sludge recycling ratios. (a) TMP increase; (b) TMP at day 10.

\subsection{Impact of Coagulation Stirring Strategy on Sedimentation and UF Performance}

The coagulation stirring strategy is another factor impacting the coagulation and UF system during sludge recycling. The coagulation stirring strategy discussed in this paper mainly refers to the stages of velocity gradients, which are regulated and controlled by the stirring speed and hydraulic retention time in the coagulation tank. During traditional coagulation (without sludge recycling), the complete coagulation procedure (contains rapid, moderate and slow stirring mixing) has the highest coagulation efficiency. However, when adding the sludge into the feed water, the solid content of the mixture was in the range of $2 \mathrm{~g} / \mathrm{L}$ to $10 \mathrm{~g} / \mathrm{L}$, with the sludge recycling ratio $5 \%$ to $20 \%$, the solid content in the recycle stream is several orders of magnitude higher than the traditional coagulation process (solid content mostly less than $100 \mathrm{mg} / \mathrm{L}$ ) without sludge recycling. Hence floc growth of flocculation during the traditional coagulation process might not occur when adding sludge. For this reason, the complete coagulation stirring strategy is probably not necessary anymore, and choosing the appropriate coagulation stirring strategy is necessary. Four kinds of coagulation stirring strategy were tested (No. 1-No. 4). Detailed information of the coagulation stirring strategy is given in Table 2. The sludge recycling ratio was here maintained at $10 \%$ as the optimal value (Sections 3.3 and 3.4). 
Table 2. Detailed information of the coagulation stirring strategy.

\begin{tabular}{cc}
\hline No. & Coagulation Stirring Strategy \\
\hline $\begin{array}{c}\text { No. } 1 \\
\text { the raw water is rapidly mixed in the first stirring tank, and then flows into the sediment tank } \\
\text { the raw water is stirred in the first and second stirring tank in series, and then flows into } \\
\text { sediment tank }\end{array}$ \\
No. 3 the raw water is stirred in the first, second and third stirring tank in series, and then flows into \\
sediment tank
\end{tabular}

Figure 6 shows the sedimentation efficiency of different coagulation stirring strategies. It can be observed that the sedimentation efficiency is negatively impacted at a moderate and slow stirring rate. Using No. 1 coagulation stirring strategy the minimum $\mathrm{T}_{1 / 2}(113 \mathrm{~s})$ was obtained. When the influent was subsequently treated with a moderate/slow stirring process (see No. 2-No. 4), $\mathrm{T}_{1 / 2}$ increases. Especially when using the complete coagulation stirring strategy (No. 4), $\mathrm{T}_{1 / 2}$ was the highest. This phenomenon leads to the speculation that the coagulation stirring strategy might change during the sludge recycling enhanced coagulation process. This suggests that only a sufficient mixing of sludge and raw water is needed during the enhanced coagulation process and the complete coagulation strategy could impede the sedimentation efficiency.

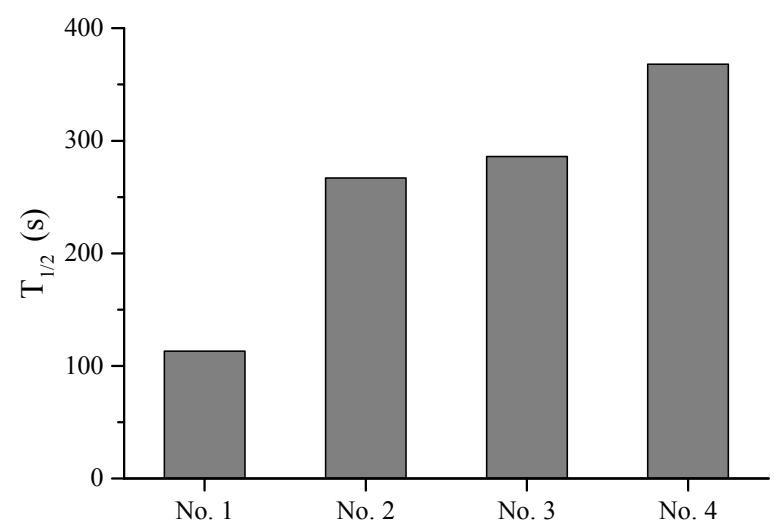

Figure 6. Sedimentation efficiencies for the different coagulation stirring strategies.

Figure 7 shows the TMP with different coagulation stirring strategies. Figure 7a shows the TMP increase with different coagulation stirring strategies. The TMP increase when no sludge recycling was applied reflects severe membrane fouling, compared with the approach with sludge recycling. Moreover, membrane fouling was also impacted by the coagulation stirring strategy. The TMP of the complete coagulation strategy (No. 4) is higher than the other three coagulation stirring strategies, which demonstrates that the complete coagulation strategy is not applicable during the sludge recycling enhanced coagulation-UF process. The coagulation stirring strategy of rapid mixing (No. 1) yields the lowest increase of TMP among the five conditions. This suggests that shortening the coagulation duration and procedure is necessary and positive to reduce membrane fouling. Figure $7 \mathrm{~b}$ shows the reversibility of membrane fouling during the tenth day of the different coagulation stirring strategies. The irreversible membrane fouling of the No. 1 coagulation stirring strategy is lower than that of others, which means that rapid mixing as coagulation stirring strategy could prevent the foulants from penetrating into the membrane pores. 

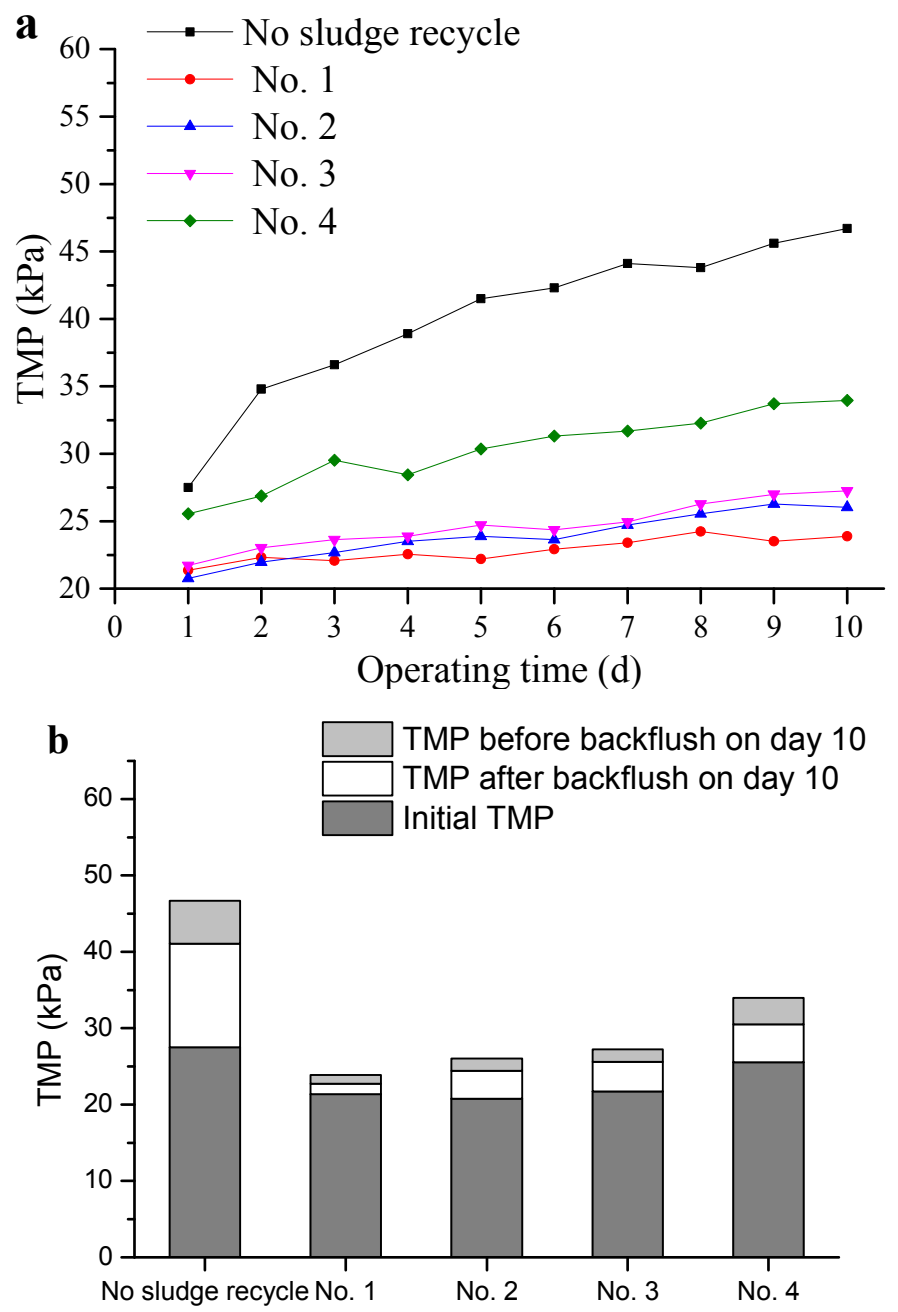

Figure 7. TMP with different coagulation stirring strategies. (a) TMP increase; (b) TMP of the day 10.

\subsection{Impact of the Coagulation Stirring Strategy on the Removal Efficiency}

Figure 8 presents the ammonia removal efficiency of different coagulation stirring strategies after the membrane process. However, during the discussion of sludge recycling ratio, we only analyze the removal efficiency of the enhanced coagulation process. When compared with the ammonia before the membrane without sludge recycling, the improvement of ammonia nitrogen removal efficiency is limited by the UF membrane. This suggests that UF has poor removal efficiency for small molecular substances. However, sludge recycling, irrespective of the coagulation stirring strategy, could improve the removal efficiency of ammonia nitrogen by $60 \%$. However, the removal of ammonia nitrogen remains at a similar level for different coagulation stirring strategies, which suggests that the coagulation stirring strategy could hardly impact the ammonia removal efficiency.

Figure 9 shows the organic matter removal efficiency of the sludge recycling enhanced coagulation process with different coagulation stirring strategies after the membrane process. The organic matter removal efficiency, both DOC removal and $\mathrm{UV}_{254}$ removal, were limited with the coagulation-UF process without sludge recycling, when compared with the removal efficiency before the membrane. It can be concluded that the membrane can hardly remove the dissolved organic matter. This is in accordance with the ammonia nitrogen removal. For the coagulation process enhanced with sludge recycling, the removal efficiency can be improved. Moreover, the removal efficiency of quick mixing (No. 1) has the highest organic removal efficiency. This means that moderate and slow 
stirring can impede the DOC and $\mathrm{UV}_{254}$ removal efficiency during the sludge recycling enhanced coagulation-UF process.

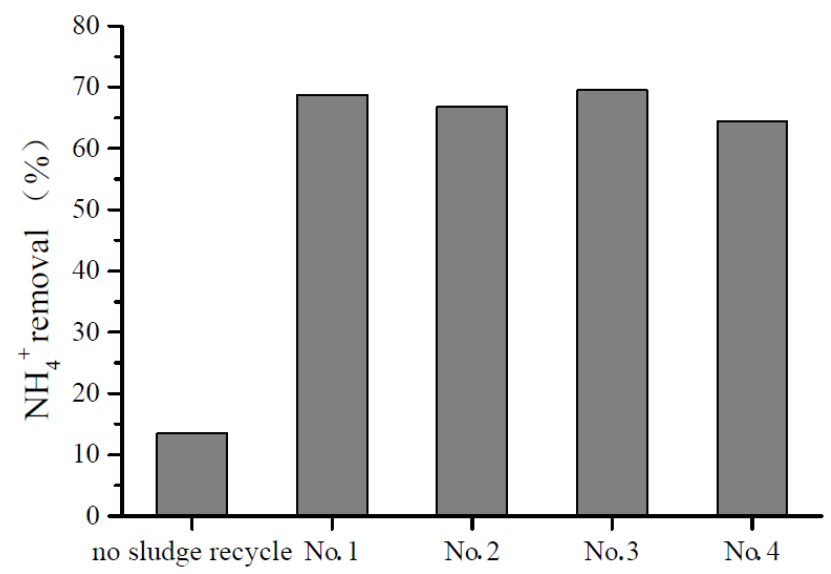

Figure 8. Ammonia nitrogen removal efficiencies for different coagulation stirring strategies.
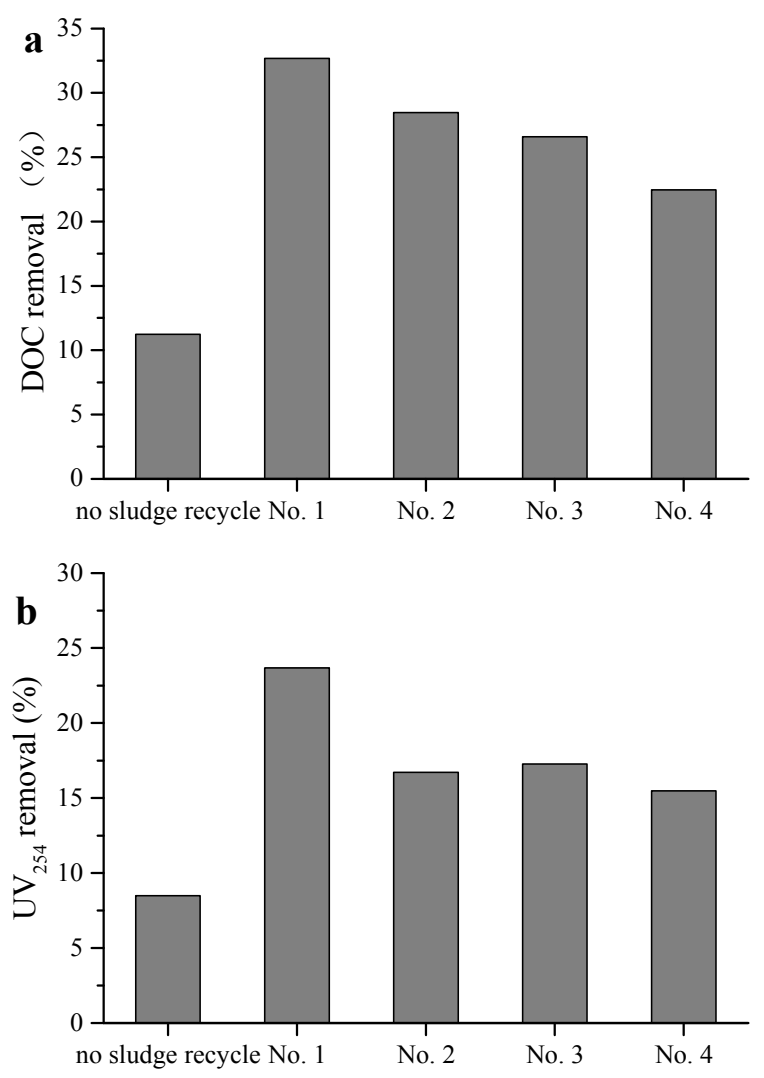

Figure 9. DOC (a) and $\mathrm{UV}_{254}$ (b) removal efficiencies using different coagulation stirring strategies.

\subsection{Optimization of Sludge Recycling Ratio and Coagulation Stirring Strategy}

The sludge recycling ratio and coagulation stirring strategy are two factors impacting the enhanced coagulation-UF process. However, when the ratio is too high, this improvement may impede the sedimentation efficiency. In this study, when the recycle ratio was over $10 \%$, the improvements for ammonia and DOC removal were limited, and the sedimentation efficiency was impeded as well, which also negatively impacted the membrane fouling performance. Based on the results of removal 
efficiency, sedimentation efficiency, and membrane fouling control shown in Sections 3.1 and 3.2, the optimum sludge recycling ratio was determined to be $10 \%$.

The coagulation stirring strategy may also impact the performance of the enhanced coagulation-UF process. During the recycle process, the coagulation theory could be changed. Figure 10 shows the particle distribution of sludge during the rapid mixing conditions, which shows that the average sludge particle size is around $50 \mu \mathrm{m}$. This average particle size is much bigger than the floc size during the rapid mixing period. Yu et al [25] studied the variation of average floc size with different dosage of alum, the size was below $60 \mu \mathrm{m}$, which suggest that the sludge particle size could be comparable to the alum floc during the entire traditional coagulation process. For instance, at a recycling ratio of $10 \%$, the solid content of mixed water is in the range of 4 to $5 \mathrm{~g}$ per liter, which is much higher than the solid content of raw water. The DLVO theory is the main theory for traditional coagulation. In the DLVO theory, the molecules can decrease their surface electrical charge according to the coagulant dosing, and then aggregate by overcoming the repulsion potential. After the initial aggregation the floc grows bigger and then flocculates [26]. The DLVO theory is not appropriate when sludge recycling applied since the solid content is very high, and the floc in the sludge is large compared with the molecules in the raw water. The complete coagulation stirring strategy obeys the traditional coagulation theory, but the strategy should be modified during sludge recycling enhancement since the aggregation is substituted by adsorption of sludge. Rapid mixing mixes the solid content and the raw water completely, while moderate/slow stirring impedes the coagulation enhancement. Shortening the coagulation process could also save energy UF and coagulant dosage. The sludge recycling could also aid with ammonia nitrogen and organic removal due to adsorption on sludge. From the sludge particle, we assume that adsorption of sludge should be a possible reason for the improvement of ammonia and organic removal efficiency. A biological effect may also occur for suitable conditions for microbial growth. Because of the limited organic removal efficiency of UF, the combination of sludge recycling with coagulation stirring strategy No. 1 and UF could provide a high efficiency for drinking water treatment.

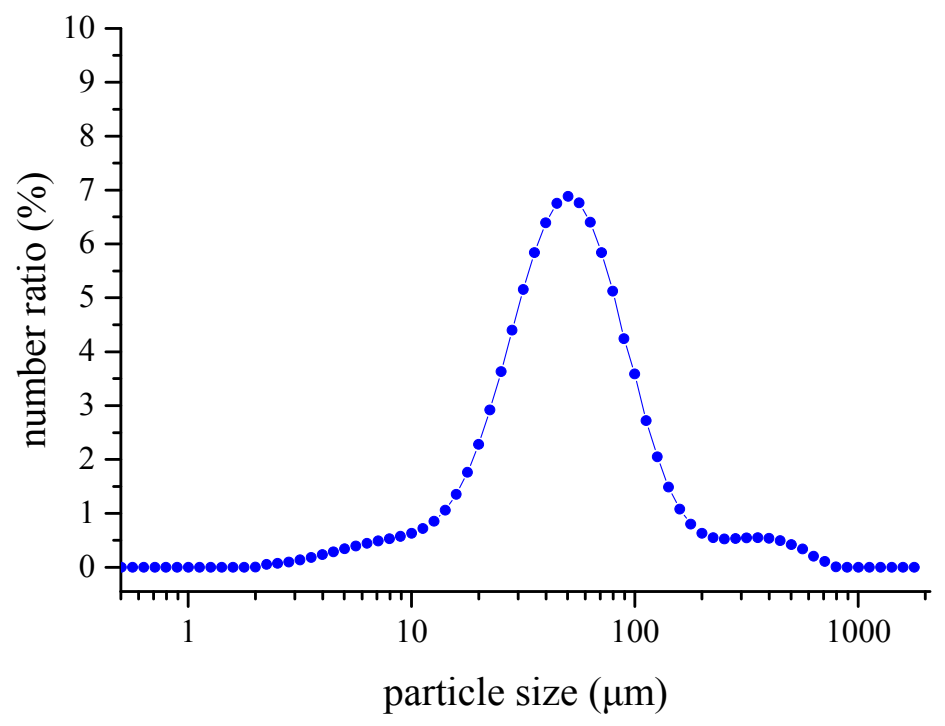

Figure 10. Particle size distributions of sludge in the sludge recycling tank. The sludge was produced at rapid mixing conditions.

\section{Conclusions}

A pilot-scale study of sludge recycling enhanced coagulation-UF was presented in this paper. Two factors for sludge recycling enhanced coagulation-UF, including sludge recycling ratio and coagulation stirring strategy, were discussed in this study. 
(1) The sludge recycling at a ratio of $10 \%$ achieved the highest sedimentation efficiency and the best pollutant removal (ammonia and dissolved organics) in the sludge recycling enhanced coagulation-UF process. Moreover, membrane fouling was mitigated during this condition, which suggested that the sludge recycling contributed to energy saving.

(2) Rapid mixing had the best performance in terms of enhancing the coagulation-UF process. A traditional coagulation stirring strategy should be modified when using the sludge recycling enhanced coagulation-UF process.

(3) The DLVO theory is not appropriate during sludge recycling enhancement. The effect of overcoming the repulsion potential might not play a leading role, since the sludge particle size and solid content of mixed water were much higher than the raw water.

(4) The adsorption of sludge could be a possible reason for pollutant removal by the sludge recycling enhanced coagulation-UF process.

Acknowledgments: This work was financially supported by Natural Science Foundation of China (Grant 51308146), an Open Project of the State Key Laboratory of Urban Water Resource and Environment (ES201511-02), a fund from China Postdoctoral Science Foundation (Grants 2015T80360), a Heilongjiang Postdoctoral Fund (Grants LBH-TZ1612), and the China Scholarship Council. Thanks also go to the Nanjiao water treatment plant for providing the facilities.

Author Contributions: Bin Liu and Fangshu Qu conceived and designed the experiments; Bin Liu performed the experiments; Shaodong Guo and Huarong Yu analyzed the data; Heng Liang and Guibai Li contributed reagents/materials/analysis tools; Bin Liu wrote the paper and Bart Van der Bruggen polish the paper.

Conflicts of Interest: The authors declare no conflict of interest.

\section{References}

1. Lai, C.-H.; Chou, Y.-C.; Yeh, H.-H. Assessing the interaction effects of coagulation pretreatment and membrane material on UF fouling control using HPSEC combined with peak-fitting. J. Membr. Sci. 2015, 474, 207-214. [CrossRef]

2. Chang, H.Q.; Liang, H.; Gao, W.; Li, G.B. Purification of micro-polluted reservoir water from the yellow river by membrane bioreactors combined with pretreatments. J. Harbin Inst. Technol. 2012, 44, 25-31.

3. Gao, W.; Liang, H.; Ma, J.; Han, M.; Chen, Z.L.; Han, Z.S.; Li, G.B. Membrane fouling control in ultrafiltration technology for drinking water production: A review. Desalination 2011, 272, 1-8. [CrossRef]

4. Yu, W.; Xu, L.; Qu, J.; Graham, N. Investigation of pre-coagulation and powder activate carbon adsorption on ultrafiltration membrane fouling. J. Membr. Sci. 2014, 459, 157-168. [CrossRef]

5. Amy, G. Fundamental understanding of organic matter fouling of membranes. Desalination 2008, 231, 44-51. [CrossRef]

6. Qi, L.; Liang, H.; Wang, Y.; Li, G.B. Integration of immersed membrane ultrafiltration with the reuse of PAC and alum sludge (RPAS) process for drinking water treatment. Desalination 2009, 249, 440-444. [CrossRef]

7. Cheng, H.; Zhang, Y.; Wang, X.; Cheng, F.; Han, J.; Zhao, J.; Wang, N.; Sun, Y. Theoretical and experimental investigation of time-varying properties in the coagulation of kaolinite containing wastewater by gypsum. J. Taiwan Inst. Chem. Eng. 2017, 71, 253-259. [CrossRef]

8. Volkova, A.V.; Ermakova, L.E.; Golikova, E.V. Peculiarities of coagulation of the pseudohydrophilic colloids: Aggregate stability of the positively charged $\gamma-\mathrm{Al}_{2} \mathrm{O}_{3}$ hydrosol in $\mathrm{NaCl}$ solutions. Colloids Surf. A Physicochem. Eng. Asp. 2017, 516, 129-138. [CrossRef]

9. Tang, H.; Xiao, F.; Wang, D. Speciation, stability, and coagulation mechanisms of hydroxyl aluminum clusters formed by PACL and alum: A critical review. Adv. Colloid Interface Sci. 2015, 226, 78-85. [CrossRef] [PubMed]

10. Dixon, M.B.; Richard, Y.; Ho, L.; Chow, C.W.K.; O’Neill, B.K.; Newcombe, G. A coagulation-powdered activated carbon-ultrafiltration-Multiple barrier approach for removing toxins from two Australian cyanobacterial blooms. J. Hazard. Mater. 2011, 186, 1553-1559. [CrossRef] [PubMed]

11. Zhou, Z.; Yang, Y.; Li, X.; Gao, W.; Liang, H.; Li, G. Coagulation efficiency and flocs characteristics of recycling sludge during treatment of low temperature and micro-polluted water. J. Environ. Sci. 2012, 24, 1014-1020. [CrossRef] 
12. Bai, L.; Qu, F.; Liang, H.; Ma, J.; Chang, H.; Wang, M.; Li, G. Membrane fouling during ultrafiltration (UF) of surface water: Effects of sludge discharge interval (SDI). Desalination 2013, 319, 18-24. [CrossRef]

13. Qu, F.; Liang, H.; Tian, J.; Yu, H.; Chen, Z.; Li, G. Ultrafiltration (UF) membrane fouling caused by cyanobateria: Fouling effects of cells and extracellular organics matter (EOM). Desalination 2012, 293, 30-37. [CrossRef]

14. Baek, Y.W.; An, Y.J. Microbial toxicity of metal oxide nanoparticles $\left(\mathrm{CuO}, \mathrm{NiO}, \mathrm{ZnO}\right.$, and $\left.\mathrm{Sb}_{2} \mathrm{O}_{3}\right)$ to Escherichia coli, Bacillus subtilis, and Streptococcus aureus. Sci. Total Environ. 2011, 409, 1603-1608. [CrossRef] [PubMed]

15. Yang, Y.L.; Sun, M.; Li, X.; Yu, W.Z.; Li, G.B. Study on the influence of alkalinity on floc formation, breakup and regrowth by photometric dispersion analyzer. Opt. Tech. 2010, 36, 474-478.

16. Liu, B.; Liang, H.; Qu, F.; Chang, H.; Shao, S.; Ren, N.; Li, G. Comparison of evaluation methods for microcystis cell breakage based on dissolved organic carbon release, potassium release and flow cytometry. Chem. Eng. J. 2015, 281, 174-182. [CrossRef]

17. Aguilar, M.I.; Sáez, J.; Lloréns, M.; Soler, A.; Ortuño, J.F. Nutrient removal and sludge production in the coagulation-flocculation process. Water Res. 2002, 36, 2910-2919. [CrossRef]

18. Liu, T.; Lian, Y.; Graham, N.; Yu, W.; Rooney, D.; Sun, K. Application of polyacrylamide flocculation with and without alum coagulation for mitigating ultrafiltration membrane fouling: Role of floc structure and bacterial activity. Chem. Eng. J. 2017, 307, 41-48. [CrossRef]

19. Liao, Z.-L.; Chen, H.; Zhu, B.-R.; Li, H.-Z. Combination of powdered activated carbon and powdered zeolite for enhancing ammonium removal in micro-polluted raw water. Chemosphere 2015, 134, 127-132. [CrossRef] [PubMed]

20. Tian, J.Y.; Chen, Z.L.; Liang, H.; Li, X.; Wang, Z.Z.; Li, G.B. Comparison of biological activated carbon (BAC) and membrane bioreactor (MBR) for pollutants removal in drinking water treatment. Water Sci. Technol. 2009, 60, 1515-1523. [CrossRef] [PubMed]

21. Yu, H.; Qu, F.; Sun, L.; Liang, H.; Han, Z.; Chang, H.; Shao, S.; Li, G. Relationship between soluble microbial products (SMP) and effluent organic matter (EFOM): Characterized by fluorescence excitation emission matrix coupled with parallel factor analysis. Chemosphere 2015, 121, 101-109. [CrossRef] [PubMed]

22. Huang, H.; Zhang, P.; Zhang, Z.; Liu, J.; Xiao, J.; Gao, F. Simultaneous removal of ammonia nitrogen and recovery of phosphate from swine wastewater by struvite electrochemical precipitation and recycling technology. J. Clean. Prod. 2016, 127, 302-310. [CrossRef]

23. Rasool, K.; Ahn, D.H.; Lee, D.S. Simultaneous organic carbon and nitrogen removal in an anoxic-oxic activated sludge system under various operating conditions. Bioresour. Technol. 2014, 162, 373-378. [CrossRef] [PubMed]

24. Tian, J.Y.; Chen, Z.L.; Nan, J.; Liang, H.; Li, G.B. Integrative membrane coagulation adsorption bioreactor (MCABR) for enhanced organic matter removal in drinking water treatment. J. Membr. Sci. 2010, 352, 205-212. [CrossRef]

25. Yu, W.; Gregory, J.; Campos, L.C. Breakage and re-growth of flocs formed by charge neutralization using alum and polydadmac. Water Res. 2010, 44, 3959-3965. [CrossRef] [PubMed]

26. Chang, H.; Qu, F.; Liu, B.; Yu, H.; Li, K.; Shao, S.; Li, G.; Liang, H. Hydraulic irreversibility of ultrafiltration membrane fouling by humic acid: Effects of membrane properties and backwash water composition. J. Membr. Sci. 2015, 493, 723-733. [CrossRef]

(C) 2017 by the authors. Licensee MDPI, Basel, Switzerland. This article is an open access article distributed under the terms and conditions of the Creative Commons Attribution (CC BY) license (http:/ / creativecommons.org/licenses/by/4.0/). 